\title{
Higher health effects of ambient particles during the warm season: The role of infiltration factors
}

\author{
Stefano Zauli-Sajani ${ }^{\mathrm{a}, *}$, Sabrina Rovelli ${ }^{\mathrm{b}}$, Arianna Trentini ${ }^{\mathrm{c}}$, Dimitri Bacco ${ }^{\mathrm{c}}$, Stefano Marchesi ${ }^{\mathrm{a}}$, Fabiana Scotto ${ }^{\mathrm{c}}$, \\ Claudia Zigola ${ }^{\mathrm{d}}$, Paolo Lauriola ${ }^{\mathrm{a}}$, Domenico Maria Cavallo ${ }^{\mathrm{b}}$, Vanes Poluzzi ${ }^{\mathrm{c}}$, Andrea Cattaneo ${ }^{\mathrm{b}}$, Otto Hänninen ${ }^{\mathrm{e}}$ \\ ${ }^{a}$ Regional Centre for Environment and Health, Arpae Emilia-Romagna, Via Begarelli, 13, 41121 Modena, Italy \\ b Department of Science and High Technology, Università degli Studi dell'Insubria, Via Valleggio 11, 22100 Como, Italy \\ ' Regional Centre for Urban Areas, Arpae Emilia-Romagna, Largo Caduti del Lavoro, 6, 40122 Bologna, Italy \\ d Provincial District of Ravenna, Arpae Emilia-Romagna, Via Alberoni, 17/19, 48121 Ravenna, Italy \\ e National Institute for Health and Welfare, Kuopio, Finland
}

\section{H I G H L I G H T S}

- Analysis of the causes of the apparent seasonal differences in PM toxicity

- Experimental study carried out using a simulated ventilation patterns in a test house

- Indoor and outdoor measurements of chemical composition and size distribution

- Higher concentrations of nano particles and sulfates indoors during summer

- Few deviations of infiltration factors calculated from pooled chemical components

\section{A R T I C L E I N F O}

\section{Article history:}

Received 25 August 2017

Received in revised form 19 January 2018

Accepted 22 January 2018

Available online 28 January 2018

Editor: Jianmin Chen

\section{Keywords:}

Ambient particles

Infiltration factors

Indoor exposure

Health effects

Size distribution

Chemical components

\section{G R A P H I C A L A B S T R A C T}

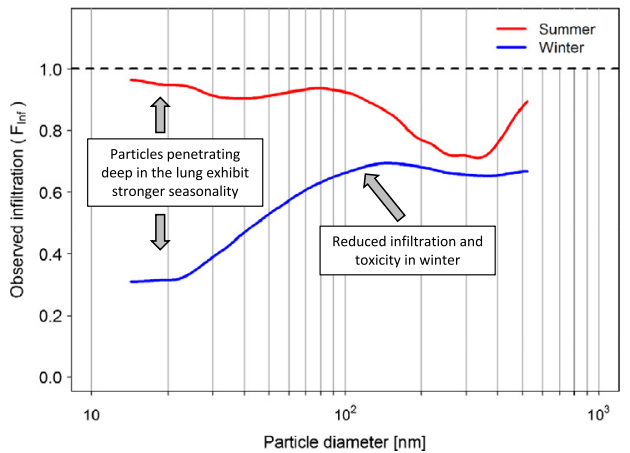

\section{A B S T R A C T}

A large number of studies have shown much higher health effects of particulate matter (PM) during the warm compared to the cold season. In this paper we present the results of an experimental study carried out in an unoccupied test apartment with the aim of understanding the reasons behind the seasonal variations of the health effects due to ambient $\mathrm{PM}_{2.5}$ exposure. Measurements included indoor and outdoor $\mathrm{PM}_{2.5}$ mass and chemical composition as well as particle size distribution of ultrafine particles. Monitoring campaigns were carried out during summer and winter following a ventilation protocol developed to replicate typical occupant behaviour according to a questionnaire-based survey. Our findings showed that seasonal variation of the relationship between ambient and indoor mass concentrations cannot entirely explain the apparent difference in PM toxicity between seasons and size distribution and chemical composition of particles were identified as other possible causes of changes in the apparent PM toxicity. A marked decrease of ultrafine particles $(<100 \mathrm{~nm})$ passing from outdoors to indoors was observed during winter; this resulted in higher indoor exposure to nanoparticles ( $<50 \mathrm{~nm})$ during summer. With regards to the chemical composition, a pooled analysis showed infiltration factors of chemical species similar to that obtained for $\mathrm{PM}_{2.5}$ mass with values increasing from 0.73 during winter to 0.90 during summer and few deviations from the pooled estimates. In particular, significantly lower infiltration factors and sink effect were found for nitrates and ammonium during winter. In addition, a marked increase in the contribution of indoor and outdoor sulfates to the total mass was observed during summer.

(c) 2018 Elsevier B.V. All rights reserved.

\footnotetext{
* Corresponding author.

E-mail address: szauli@arpae.it (S. Zauli-Sajani).
} 


\section{Introduction}

Atmospheric aerosol has been documented to cause increased mortality, morbidity, decreased lung function and other adverse effects upon health (Beelen et al., 2014; Raaschou-Nielsen et al., 2013) with greater effects on frailty and elderly people (Alessandrini et al., 2016). While a body of evidence has been accumulating over the last few decades especially in relation to cardiovascular and respiratory diseases, there is still considerable uncertainty about the mechanisms of action linked to the health effects and about which physical and/or chemical characteristics of particulate matter (PM) are most important as determinants of health (REVIHAAP, 2013; Kelly and Fussell, 2012; Brunekreef and Holgate, 2002; Harrison and Yin, 2000). Recently, toxicological and epidemiological studies have focused on health effects from exposure to ultrafine particles (UFP, particles with diameter $<$ $100 \mathrm{~nm}$ ) due to their toxicity and ability to penetrate deeply in human lungs (Lanzinger et al., 2016; Peters et al., 2011), and to the chemical composition of particles (Raaschou-Nielsen et al., 2016; Basagaña et al., 2015).

Moreover, a number of studies have shown higher effects during the warm compared to the cold season. For example, higher effect of $\mathrm{PM}_{10}$ on mortality in summer was observed in several studies conducted in European countries (Stafoggia et al., 2008; Nawrot et al., 2007). More recently, Samoli et al. (2013) in an international meta-analysis involving major cities in the Mediterranean area found much stronger associations between mortality and $\mathrm{PM}_{2.5}$ for exposures during warm months (April-September) compared with colder months (October-March). In particular, percent increases in all-cause mortality associated with a 10 $\mu \mathrm{g} / \mathrm{m}^{3}$ increases in $\mathrm{PM}_{2.5}$ increased from $0.23 \%$ to $2.24 \%$. The variation was from $0.48 \%$ to $2.6 \%$ for cardiovascular mortality and from $1.74 \%$ to $6.46 \%$ for respiratory mortality. Marked seasonal variations were also found in an Italian meta-analysis (Biggeri et al., 2005) with summer percent increase in natural mortality much higher during the warm season ( $1.95 \%)$ compared to the whole year $(0.31 \%)$. The trend in the health effects is opposite to the trend of the ambient PM concentrations which in mid-latitude areas is normally higher during the cold season, due to lower mixing heights of the troposphere and higher frequency of stability conditions (Bigi and Harrison, 2010).

Findings from American studies were in good agreement with Europeans. Chen et al. (2012) estimated the seasonal percent increase in short-term mortality per $10 \mu \mathrm{g} / \mathrm{m}^{3}$ increase in $\mathrm{PM}_{10}$ for seven U.S. regions using data from 100 U.S. cities included in the National Morbidity, Mortality, and Air Pollutions Study (NMMAPS). Higher risks during the summer season came out considering all pooled areas with a marked increase in the north-eastern regions.

Several Asian studies conducted in Shenyang, China (Ma et al., 2011), Bangkok, Thailand (Wong et al., 2008) and Seoul, South Korea (Kim et al., 2015; Park et al., 2011; Yi et al., 2010) also confirmed this seasonal pattern in the health effects. We can conclude that higher toxicity of particles during the warm season seems not related to specific areas.

The reason behind this marked temporal trend of the short-term health effects of airborne particles is not well known even though it is believed that at least part of this effect could be attributed to the seasonal variation of the relationship between ambient concentrations and personal exposure. In fact, the human exposure in epidemiological studies is usually assigned at population level using data from central monitoring stations, i.e. from data referred to ambient pollution. However, it is well known that not only a relevant contribution to the personal exposure comes from indoor sources, but also that the exposure to ambient PM mainly occurs indoors (Hänninen et al., 2017; Meier et al., 2015a; Cattaneo et al., 2011).

A given increase in the concentration of outdoor PM can result in varying increases in indoor and personal PM exposure, owing to various parameters that influence the indoor exposure to outdoor pollution. Important factors include the air change rate (the rate at which indoor air is replaced with outdoor air via natural or forced ventilation; Hänninen et al., 2004), the changes in size distribution of PM transported indoors from outdoors (Hänninen et al., 2013), the presence of air conditioning $(A C)$, the fraction of time that cooling and heating occurs, and the amount of time that people spend indoors. Most of the above mentioned factors change with season as can be seen in the seasonal variability of infiltration (Hänninen et al., 2011) and it is reasonable to assume that they may induce a seasonal trend in the relationship between the actual population exposure and the concentrations measured by monitors located within urban areas.

The general objective of this study, conducted in the framework of the "Supersito" project, is to quantify the seasonal differences in infiltration factors of different particle metrics using a simulated ventilation pattern in a test house. Indoor and outdoor measurements of $\mathrm{PM}_{2.5}$ mass and chemical composition, as well as size distribution were conducted during the heating and non-heating season in order to interpret seasonal differences in the health effects.

Specifically, our aims are to (i) quantify the seasonal relationship between unit increase in $\mathrm{PM}_{2.5}$ ambient concentrations and corresponding increase in indoor concentrations; (ii) estimate seasonal differences in indoor and outdoor $\mathrm{PM}_{2.5}$ chemical composition (metals, carbon fractions and ions) and size distribution and (iii) analyze infiltration rates for different particle metrics, applying a novel approach to estimate the infiltration rates for chemical components.

\section{Materials and methods}

\subsection{Ambient particle infiltration}

To understand the link between ambient PM concentrations and indoor exposures we have to consider the ambient particle penetration and the indoor fate of ambient particles. Indoor concentration profiles are described by the mass balance equation (Diapouli et al., 2013)

$$
\frac{d C_{i n}}{d t}=a \cdot P \cdot C_{o u t}-(a+k) \cdot C_{i n}+\frac{Q_{i s}}{V}
$$

where $C_{\text {in }}$ and $C_{\text {out }}$ are the indoor and outdoor concentrations of particles, respectively $\left(\mu \mathrm{g} / \mathrm{m}^{3}\right) ; a$ is the air exchange rate $\left(\mathrm{h}^{-1}\right) ; P$ is the dimensionless penetration efficiency of particles; $k$ the deposition rate of particles $\left(\mathrm{h}^{-1}\right) ; V$ the volume of the indoor area $\left(\mathrm{m}^{3}\right)$; and $Q_{i s}$ the indoor particle generation rate $(\mathrm{mg} / \mathrm{h})$. The equation assumes perfect mixing and ignores particle mass losses or gains due to differences in gas-phase concentrations of condensable species and temperature/relative humidity conditions between indoors and outdoors.

If both indoor particle generation and resuspension are assumed to be negligible (as should be the case of our test house) and a suitable long period of time is chosen so that a steady-state indoor concentration of particles is achieved the previous equation becomes

$C_{\text {in }}=P \frac{a}{a+k} C_{\text {out }}$

The coefficient that links $C_{i n}$ and $C_{\text {out }}$ is called infiltration factor $\left(F_{\text {inf }}\right)$ and represents the equilibrium fraction of ambient particles that penetrate indoors and remain suspended. $F_{\text {inf }}$ can be estimated as the slope of linear regression between indoor and outdoor concentrations. For suitably long periods when no particles are generated from indoor sources, the regression lines are expected to pass through the origin and the infiltration factor is equivalent to the indoor/outdoor ratio.

$F_{\text {inf }}=P \frac{a}{a+k}=\frac{C_{\text {in }}}{C_{\text {out }}}$ 


\subsection{Study design and study area}

There are two main approaches that can be used to assess seasonal variations of $F_{\text {inf }}$ and the mean differences in population exposure to outdoor particles in relation to season. The first one is to measure a large number of indoor environments filtering out the effects of indoor sources and personal habits (Fuller et al., 2013; Cattaneo et al., 2011). This approach is generally the most commonly used but it has some drawbacks: i) a strong limitation in the number of indoor environments that can be monitored; ii) the type of instruments that can be used (noise level, size and other practical reasons limit the use of reference instruments); iii) the duration of the measurement campaigns in each site and iv) the large variability of personal habits and building characteristics. The alternative approach adopted in the present investigation is to choose an indoor environment with characteristics and air exchange rates typical of residential settings and carry out accurate monitoring campaigns in different seasons.

One of the key point in simulating typical indoor conditions is how to reproduce mean or at least realistic air exchange rates. We decided to focus on typical ventilation habits adopted by elderly people because elderly people are the most vulnerable to short term health effects of air pollution and the residential indoor exposure is the dominant contribution to the total exposure for this population group. This approach affected also the choice of the protocol defined to ventilate the apartment. We decided, in fact, to adopt a study design based on natural ventilation which is the most common in Europe and in particular in houses occupied by elderly people. In particular, every day the windows of the apartments were open and closed following a protocol based on the most frequent habits found in a survey carried out in Lodi, Lombardy (Urso et al., 2015), a city located in the same plan and with climatic and urban characteristics very similar to our study area. We defined different protocols for winter and summer as well as for working and weekend days. The protocol was defined on a half an hour basis. In winter windows were open every day in the morning for only half an hour while during summer the windows were kept open for about $12 \mathrm{~h}$. An overview of the scheduled time for opening and closing windows is reported in Fig. S1 in the Supplementary material.

Another important choice of the study design was to perform measurements in an uninhabited apartment, to focus on indoor exposure to ambient particles. It should be also taken into account that many studies suggest that particles of outdoor and indoor origin may have different physical and chemical characteristics (Brown et al., 2008) and probably can also cause different health effects (Zhou et al., 2013; Ebelt et al., 2005). This enforces the opportunity of focusing only on ambient particles which are the data utilized by the majority of studies as surrogate of population exposure.

The study area is the city of Modena. This is a rather polluted urban area of about 200,000 inhabitants in northern Italy. Traffic and domestic heating during the cold season are the dominant air pollution sources in the area and cause quite high levels of air pollutants. In the period 2011-2013 the city-average annual concentration of $\mathrm{PM}_{2.5}$ was 19.8 $\mu \mathrm{g} / \mathrm{m}^{3}$ (average value derived from the two fixed site monitoring stations located in the urban area). The monitoring site was a brand new apartment. It was on the third floor in a five-storey building near the city centre. The total area of the apartment was $55 \mathrm{~m}^{2}$ with a ceiling height of $2.7 \mathrm{~m}$. The floor was covered with wood. The ceilings and the walls were painted with acrylic paint. The area near the monitoring site carries a moderate to high volume of traffic, and the street next to the building has a traffic load of about 39,000 vehicles ( $1 \%$ heavy duty vehicles) each working day. The building is located in a broad (30 m) two-way street with buildings of different heights at both sides. Figs. S2 and S3 show a map of the apartment and give a bird's eye view of the surroundings of the monitoring sites.

Two monitoring campaigns were conducted in the period JulyDecember 2014. Each monitoring campaign lasted 15 days: 1st campaign from 2 to 17 July (referred to in the text as "summer"), 2nd campaign from 4 to 18 December (referred in the text as "winter", following the meteorological definition).

\subsection{Instrumentation and monitoring procedure}

Two identical gravimetric samplers (Skypost PM, TCR TECORA Instruments, Corsico, Milan, Italy) were operated to measure indoor and outdoor daily $\mathrm{PM}_{2.5}$ concentrations at a flow rate of $2.3 \mathrm{~m}^{3} \mathrm{~h}^{-1}$. The instruments were placed indoor in the middle of the living room and outdoor in a balcony. Samples were collected on quartz fiber filters (Whatman, $47 \mathrm{~mm}$ diameter) and weighed following the procedure outlined in European Standard EN 12341:2014.

$\mathrm{PM}_{2.5}$ samples were analyzed for various chemical species: ions (nitrates, sulfates, ammonium), carbonaceous species (elemental carbon EC - and organic carbon - OC), and metals (arsenic, iron, manganese, vanadium, cadmium, lead, tin, antimony and lanthanum). In this paper we present results of the chemical species having $>50 \%$ of indoor and outdoor contemporary data above the limit of quantification (LOQ). LOQs for chemical components are reported in the Supplementary Information (Table S1). Methods and procedures used for the chemical speciation can be found in detail elsewhere (Zauli-Sajani et al., 2015; ZauliSajani et al., 2016). Due to the availability of a unique filter for each day and measuring site, the chemical speciation was performed sequentially every three days for metals, ions, and carbon (EC and OC). During winter, EC and OC were measured on an $8 \mathrm{~h}$ basis in order to avoid filter overload (Costa et al., 2016).

A Fast Mobility Particle Sizer (FMPS model 3091; TSI, Shoreview, MN, USA) was used to measure the particle size distributions and to estimate the ultrafine particle (UFP) concentrations. The FMPS was developed based on electrical aerosol spectrometer technology (Tammet et al., 2002). The FMPS spectrometer measured the size and number concentration of particles from $5.6 \mathrm{~nm}$ to $560 \mathrm{~nm}$ with 32 size bins every $1 \mathrm{~s}$. Size bins below $13 \mathrm{~nm}$ were not included in the analysis because of the amount of data below the detection limit and also because of artifacts in the size distribution observed in other studies (Kaminski et al., 2013; Jeong and Evans, 2009). UFP concentrations were obtained summing the number of particles detected in the channels between 13 and $100 \mathrm{~nm}$. Raw data were recorded every minute. Hourly and daily averages were derived from 1-minute data and used in the analyses.

Indoor and outdoor size distributions were obtained by coupling the FMPS with a switching system (Mod 11sc200, Pneumoidraulica Engineering S.r.l., Vicenza, Italy). The switching systems allowed for sampling from indoor and outdoor air, switching from one to the other within a time frame set by the user. A valve installed in the system could switch between sampling from the outdoor air, or from the indoor air. After the valve switched, there was a short time delay before the air from the sampled environment reached the instruments, which was the time the air travelled from the valve to the instruments. The system switched every 10 min between the indoor and outdoor measurements. In order to avoid the possibility of mixing of the outdoor and indoor air streams, the 2-min samples taken at the beginning of each 10 -min period were deleted from the database. Particles were sampled indoor and outdoor through two 3/8 in. conductive silicon sampling tubes 2 m long.

During both seasons, the indoor-outdoor air exchange rates (AERs) were estimated using the concentration decay method, employing $\mathrm{CO}_{2}$ as tracer gas (ASTM Standard E741-95). During measurements, pure $\mathrm{CO}_{2}$ was injected into the living room of the apartment for a short period of time to ensure a complete mixing with the room air, until obtaining a uniform tracer gas concentration through the space being studied (ASHRAE, 1997). The exponential decay in $\mathrm{CO}_{2}$ indoor concentrations was continuously monitored using a non-dispersive infrared analyzer (GE Sensing Telaire 7001, Goleta, CA, USA; sampling interval: $1 \mathrm{~min}$ ) provided with a battery-operated data logger (Hobo U12; Onset Computer Inc., Pocasset, MA, USA). $\mathrm{A} \mathrm{CO}_{2}$ analyzer was also placed outdoor to simultaneously monitor the corresponding outdoor 
levels. Before and after each seasonal measurement, all the monitors were set to zero through the flux of $\mathrm{N}_{2}$ at 0.5 bar and the calibration was verified in a glove bag with a certified $\mathrm{CO}_{2}$ gas bottle (1000 ppm). $\mathrm{CO}_{2}$ data were corrected a posteriori only if errors exceeded the $\pm 10 \%$. To estimate with reasonable accuracy the AERs resulting from the application of the protocols previously described for opening and closing windows, AERs measurements were carried out with closed and open windows both in the warm and cold season. For each studied period, the average exchange rates were then calculated on the basis of the applied protocols.

Indoor and outdoor data of temperature and relative humidity were obtained from two digital thermo-hygrometers (Testo 175 H2, Testo AG, Lenzkirch, Deutschland). Measurements were taken every hour.

The measurements of all parameters were conducted simultaneously indoors and outdoors.

\section{4. $Q A / Q C$ and statistical analysis}

Quality control of $\mathrm{PM}_{2.5}$ mass and chemical composition data was carried out based on residuals calculated by regression analysis between indoor and outdoor data. Data with residuals larger than three times the standard deviation of residuals were identified as anomalous.

For FMPS data quality control the following procedure was used: a) applying a $\log 10$ function on the UFP minute data; b) stratifying data in time slots of $3 \mathrm{~h}(0-3,3-6$ etc.) and calculating the summary statistics for each slot and campaign; c) classifying data as anomalous if they were higher than the mean plus three times the standard deviation for the corresponding campaign and time slot (Zauli-Sajani et al., 2015). Then we averaged non-anomalous data on an hourly and daily basis.

Summary statistics and paired $t$-test have been used to investigate differences between series of measurements while determination coefficient and regression analysis have been chosen to address temporal relationships between data.

Infiltration rates of chemical components were firstly analyzed by season with a pooled approach. The chemical data had been previously standardized based on season specific average levels to avoid problems related to different orders of magnitude of the chemical components. Then a sensitivity analysis calculating both the regression slopes from data of each chemical component and from the pooled data of all other components was carried out. The Leave One Element Out (LOEO) method was adopted to investigate whether a single component deviated from a common pattern of infiltration rate obtained from all of the other components.

Statistical data analysis was carried out using the R package (Version 3.0.1).

\section{Results and discussion}

Weather conditions during the monitoring campaigns were quite representative of the typical climatic characteristics of the area. Hourly outdoor temperature ranged from 19 to $37^{\circ} \mathrm{C}$ during summer and from 5 to $23^{\circ} \mathrm{C}$ during winter. Indoor temperatures ranged from 26 to $33^{\circ} \mathrm{C}$ during summer and from 15 to $22^{\circ} \mathrm{C}$ during winter.

AERs estimated with the concentration decay method were higher during the warm season compared to the cold period, with average values equal to 2.72 and $0.84 \mathrm{~h}^{-1}$, respectively (ratio: 3.2 ). These results were quite in line with those reported for European dwellings with similar characteristics to those of our test house (Dimitroulopoulou, 2012). Nonetheless, it is noteworthy to underline that AERs may vary with building features, personal habits and from area to area depending also on the local climate characteristics (Meng et al., 2005; Stranger et al., 2009). Cattaneo et al. (2011) measured a mean value of $0.6 \mathrm{~h}^{-1}$ in residential structures in the Lodi province during winter, whereas lower AERs compared to our results were obtained during summer $\left(1.5 \mathrm{~h}^{-1}\right)$. Also in a study conducted in California homes, AERs tended to be higher in summer (median: $1.13 \mathrm{~h}^{-1}$ ) and lower in winter (median: $0.61 \mathrm{~h}^{-1}$ ), whereas an opposite trend was observed in Texas, likely because of the reported use of conditioning systems during the warm season (Yamamoto et al., 2010). The RIOPA study reported wintertime mean AERs equal to $0.83^{-1}$ in CA homes (Meng et al., 2005). Herkel et al. (2008) collected detailed minute-by-minute user behaviour data in 21 office buildings in Germany in 2002-2003. Strong correlation between window ventilation and time of year and outdoor temperature was observed with windows kept more open in summer and warmer weather conditions. Haldi and Robinson (2009) analyzed 7 years of observations in Lausanne, Switzerland, and developed a Markov chain model for window ventilation in an office building. Andersen et al. (2013) collected window ventilation data from 15 dwellings in Denmark. They observed distinct occupant habits governing the window opening behaviour, but correlated (driven) with indoor CO2 level and outdoor temperature. Jeong et al. (2016) also studied window operation in 20 apartments in three residential buildings in Seoul. They observed dependency of window opening with cooking and cleaning activities besides the season and weather. Shi and Zhao (2016) collected window behaviour at eight residential apartments in Beijing and Nanjing, China. Statistical modeling yielded best fits with model using outdoor temperature, relative humidity, wind speed and ambient $\mathrm{PM}_{2.5}$ concentration as explanatory variable. Such models are valuable, besides modeling energy consumption, also when investigating in detail the potential differences in window ventilation and infiltration in given meteorological conditions.

\section{1. $\mathrm{PM}_{2.5}$ mass}

Outdoor $\mathrm{PM}_{2.5}$ concentrations during the monitoring campaigns were much higher during winter $\left(37.1 \mu \mathrm{g} / \mathrm{m}^{3}\right)$ compared to summer $\left(13.7 \mu \mathrm{g} / \mathrm{m}^{3}\right)$ as typical of the area ( 32.0 and $11.6 \mu \mathrm{g} / \mathrm{m}^{3}$ for the summer and winter months in the period 2014-2015). Outdoor $\mathrm{PM}_{2.5}$ temporal trend was very similar to that of the fixed site monitoring station located in a background area (Fig. S4 - Supplementary material).

As expected, infiltration factors were much higher during the warm season (0.84) compared to the cold period (0.58). It turns out that a unit increase, usually indicated as $10 \mu \mathrm{g} / \mathrm{m}^{3}$ in epidemiological studies, in ambient concentrations resulted in an indoor increase of $8.4 \mu \mathrm{g} / \mathrm{m}^{3}$ in summer and $5.8 \mu \mathrm{g} / \mathrm{m}^{3}$ in winter.

Paired $t$-test showed that the differences between indoor and outdoor $\mathrm{PM}_{2.5}$ concentrations were highly significant in winter and at the limit of statistical significance in summer ( $p$-value $=0.09$ ).

High correlations were found between indoor and outdoor levels (Fig. 1 and Table 1). The determination coefficients calculated between indoor and outdoor $\mathrm{PM}_{2.5}$ were higher during the cold compared to the warm season ( $R^{2}$ equal to 0.94 during winter and 0.69 during summer), which can be related to the fact that summer levels were quite constant during the monitoring period (in the $8-19 \mu \mathrm{g} / \mathrm{m}^{3}$ range) while winter levels varied from 7 to $67 \mu \mathrm{g} / \mathrm{m}^{3}$ (Fig. 1).

The comparison of our findings with other studies is not so easy. Most of US studies involved houses with various types of heating and air conditioning systems and this makes them generally not useful to identify seasonal differences in indoor exposure to ambient PM in naturally ventilated settings. In addition, most of the studies included inhabited homes. Thus only a few studies can be used as a direct comparison, most of them carried out in Europe. A study in Basel, Geneva and Lugano (Switzerland) (Meier et al., 2015b) included measurements in 80 homes. In the paper the authors stated that indoor measurements were conducted in less frequented rooms to capture indoor pollutants with outdoor origin. They found that the fraction of $\mathrm{PM}_{2.5}$ ambient concentrations infiltrating indoors were 0.92 in summer and 0.50 in winter (Table S4 of the cited paper).

Cyrys et al. (2004) carried out PM measurements in houses with no indoor sources of particles and no human activities with the exception of the activities related to ventilation protocol and instruments maintenance and control. Different ventilation modes were adopted (windows 

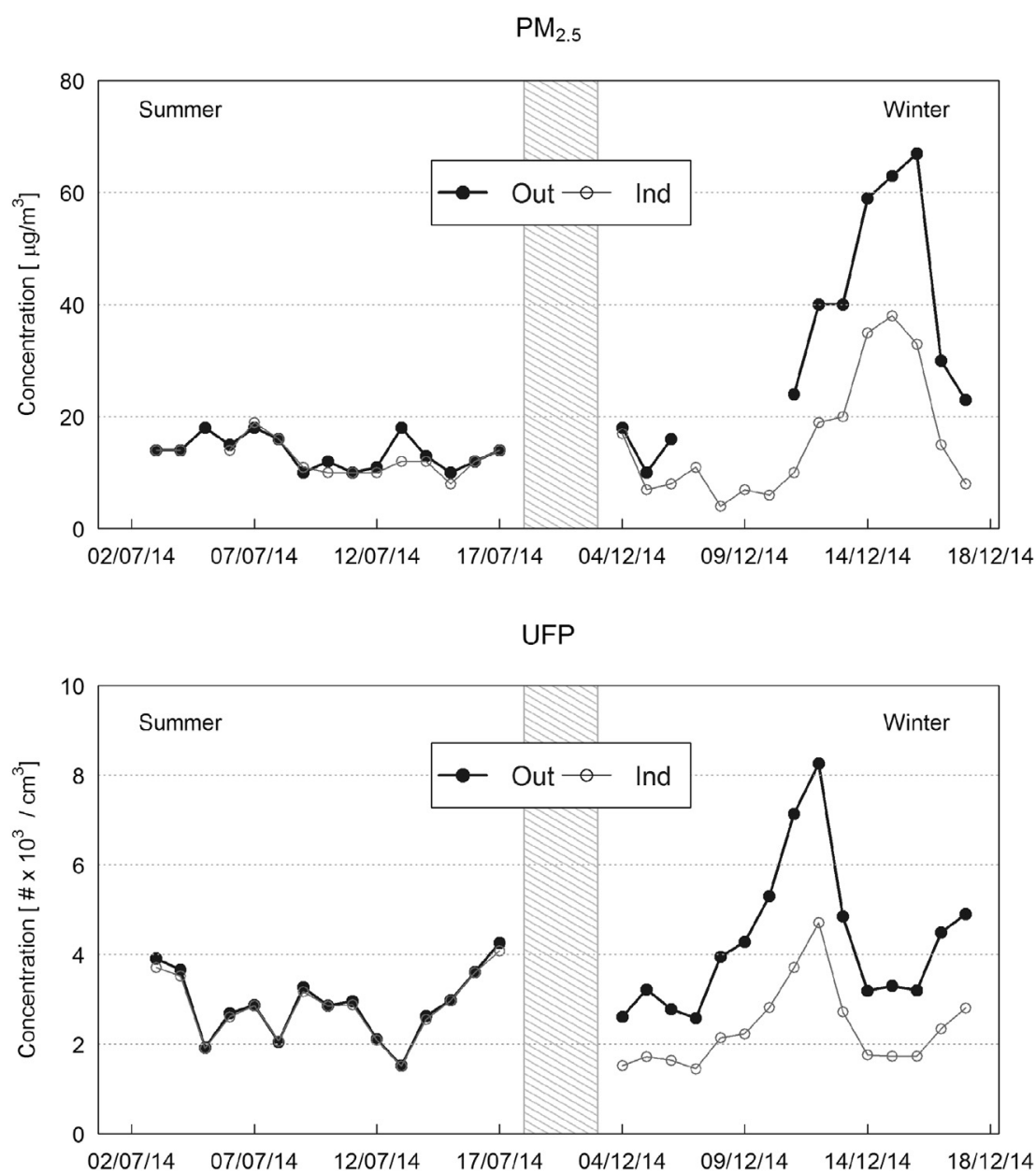

Fig. 1. Outdoor and indoor mean concentrations of $\mathrm{PM}_{2.5}$ (upper panel) and ultrafine particle (UFP) concentration (lower panel) during the two monitoring periods.

closed, windows tilted open, windows open twice a day). No analyses by season were reported in the paper but it is interesting to highlight that the authors obtained median $\mathrm{PM}_{2.5} \mathrm{I} / \mathrm{O}$ ratios equal to about 0.83 for windows tilted and 0.63 for closed windows.

Some interesting data comes also from previous campaigns carried out during the 'Supersito' project in uninhabited indoor environments. In these studies AERs were imposed to value of about 0.5 with a forced ventilation system and $\mathrm{I} / \mathrm{O}$ ratios resulted in a range between 0.5 and 0.6 for $\mathrm{PM}_{2.5}$ (Zauli-Sajani et al., 2016; Zauli-Sajani et al., 2015).

\subsection{Nano and Ultrafine particles}

Table 1 shows a summary statistics of nano particles (NP, particles $<50 \mathrm{~nm}$ ), ultrafine particles (UFP, particles $<100 \mathrm{~nm}$ ) and no-ultrafine particles (no-UFP, particles $>100 \mathrm{~nm}$ ) during the two monitoring campaigns. The temporal trends of daily indoor and outdoor UFP concentrations are reported in Fig. 1 (lower panel). While a marked increase was observed from summer to winter for ambient UFP $(+58 \%)$ and opposite trend was found for indoor UFP $(-5 \%)$, with an even larger decrease in the NP size range ( $-33 \%)$. In addition, while during summer indoor NP accounted for about $50 \%$ of the total particle number concentration, during winter the percentage dropped to $31 \%$. As expected, infiltration factors were much higher during the warm season when they reached values close to unit ( 0.98 for both NP and UFP). Contrarily, the cold season was characterized by infiltration factors significantly lower, especially for NP (0.48). High indooroutdoor correlations were found for UFP and no-UFP with higher values during summer.

Table 1

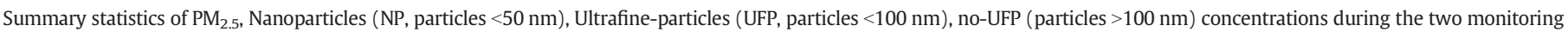

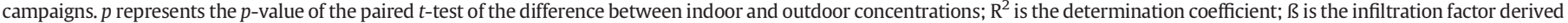
as regression slopes from indoor versus outdoor data.

\begin{tabular}{|c|c|c|c|c|c|c|c|c|c|c|}
\hline & \multicolumn{5}{|l|}{ Summer } & \multicolumn{5}{|l|}{ Winter } \\
\hline & \multirow{2}{*}{$\begin{array}{l}\text { Indoor } \\
\text { Mean (min - max })\end{array}$} & \multirow{2}{*}{$\begin{array}{l}\text { Outdoor } \\
\text { Mean }(\min -\max )\end{array}$} & \multirow[t]{2}{*}{$p$} & \multirow[t]{2}{*}{$\mathrm{R}^{2}$} & \multirow[t]{2}{*}{$\beta_{s}$} & \multirow{2}{*}{$\begin{array}{l}\text { Indoor } \\
\text { Mean (min - max })\end{array}$} & \multirow{2}{*}{$\begin{array}{l}\text { Outdoor } \\
\text { Mean }(\min -\max )\end{array}$} & \multirow[t]{2}{*}{$p$} & \multirow[t]{2}{*}{$\mathrm{R}^{2}$} & \multirow[t]{2}{*}{$\beta_{w}$} \\
\hline & & & & & & & & & & \\
\hline $\mathrm{PM}_{2.5}\left(\mu \mathrm{g} \mathrm{m}^{-3}\right)^{\mathrm{a}}$ & $12.9(8-19)$ & $13.7(10-18)$ & 0.09 & 0.69 & 0.86 & $19.1(7-38)$ & $37.1(10-67)$ & $<\mathbf{0 . 0 1}$ & 0.94 & 0.58 \\
\hline $\mathrm{NP}(\#)^{\mathrm{b}}$ & 3460 (519-9477) & $3547(338-10,156)$ & $<\mathbf{0 . 0 1}$ & 0.94 & 0.98 & $2307(635-13,757)$ & $4773(1007-25,905)$ & $<0.01$ & 0.69 & 0.48 \\
\hline $\operatorname{UFP}(\#)^{\mathrm{b}}$ & $5753(1085-12,170)$ & $5889(1203-12,572)$ & $<0.01$ & 0.94 & 0.98 & $5439(1862-21,746)$ & $9313(2444-37,291)$ & $<0.01$ & 0.76 & 0.58 \\
\hline no-UFP $(\#)^{\mathrm{b}}$ & $1260(41-2707)$ & $1368(49-3397)$ & $<\mathbf{0 . 0 1}$ & 0.94 & 0.92 & $2123(449-5301)$ & $3216(666-7411)$ & $<\mathbf{0 . 0 1}$ & 0.90 & 0.66 \\
\hline
\end{tabular}

Bold emphases means statistically significant association $(\mathrm{p}<0.05)$.

a Daily data.

b Hourly data. 
In light of these preliminary observations, these findings could be relevant to interpret the seasonal variation of PM toxicity, also if considering that recent papers showed an impressive increase of proinflammatory effect of UFP during summer (Corsini et al., 2017).

As already stated for $\mathrm{PM}_{2.5}$, only few studies may be suitable for a direct comparison and most of them have been already cited in the previous section. The study from Meier et al. (2015b) included measurements of indoor and outdoor Particle Number Concentrations (PNC). The authors found I/O ratios a bit lower compared to ours ( 0.84 in summer and 0.61 in winter). Cyrys et al. (2004) in the already mentioned paper found $\mathrm{I} / \mathrm{O}$ ratios for total particle number equal to about 0.78 for windows tilted and 0.33 for windows closed. Zauli-Sajani et al. $(2016,2015)$ in 'Supersito' monitoring campaigns with imposed AER (about $0.5 \mathrm{~h}^{-1}$ in both studies) and no indoor sources found I/O ratios for UFP close to 0.5 .

\subsection{Particle size distribution}

Fig. 2 shows the indoor and outdoor particle size distributions (PSD) for winter and summer data. While indoor and outdoor distributions were almost identical during summer, marked differences were found during winter. The summer distributions showed an important contribution from the nucleation mode and a broad plateau in the 30-70 $\mathrm{nm}$ size range. During the winter period the shape of indoor and outdoor PSD were very similar but with indoor concentrations much lower than outdoor for all particle sizes. The shapes of the distributions were quite different from the summer ones with a main mode in the accumulation size range (at about $80 \mathrm{~nm}$ ) and a secondary mode in the nucleation range $(18 \mathrm{~nm})$. Nucleation particles are produced by direct emissions from engines (Harrison et al., 2012; Charron and Harrison, 2003) and by photochemical processes with the latter contribution much higher during the summer season especially in the Mediterranean area (Hamed et al., 2007).

Size specific infiltration factors showed marked seasonal differences (Fig. 2, lower panel). Finf $_{\text {in }}$ close to unit were found during the summer season while a size dependent trend was observed during winter, with $F_{\text {inf }}$ values decreasing with decreasing particle size (for particles $<100 \mathrm{~nm}$ ), probably because of electrostatic phenomena which can contribute to hinder the infiltration of particles characterized by the smallest aerodynamic diameters (Urso et al., 2015). Similar relationships between infiltration factors and particle size were found by Long et al. (2001). The authors investigated the ambient particle infiltration considering nine nonsmoking homes in the metropolitan Boston area. Ventilation was natural with windows and doors predominantly kept closed for the heating period and typically opened during the nonheating period. Only nighttime, non-source data were retained for data analysis and modeling. Infiltration factors showed increasing trend from 0.5 at $20 \mathrm{~nm}$ to about 0.8 at $500 \mathrm{~nm}$ with much higher values during the summer season due to increased ventilation and AER.

\subsection{Chemical components of $P M_{2.5}$}

A descriptive statistics for the indoor and outdoor $\mathrm{PM}_{2.5}$ chemical components during the two investigated periods are presented in Table 2. OC represented the major component of indoor and outdoor $\mathrm{PM}_{2.5}$ both in the warm and cold season, followed by sulfates in summer and nitrates in winter (Fig. 3). Only outdoor concentrations of nitrates during winter were almost equal to OC concentrations. Metals accounted for a very small percentage of the $\mathrm{PM}_{2.5}$ mass (Fig. 3 ).

A general seasonal trend could be observed both indoors and outdoors for almost all species, with generally higher average concentrations during the cold season. The largest differences between the warm and cold period were identified for nitrates (cold/warm ratio equal to 8.5 and 20.5 for indoor and outdoor data, respectively) followed by outdoor ammonium $(\mathrm{C} / \mathrm{W}=6.6)$. This season specific trend could be somewhat expected since in winter lower temperatures
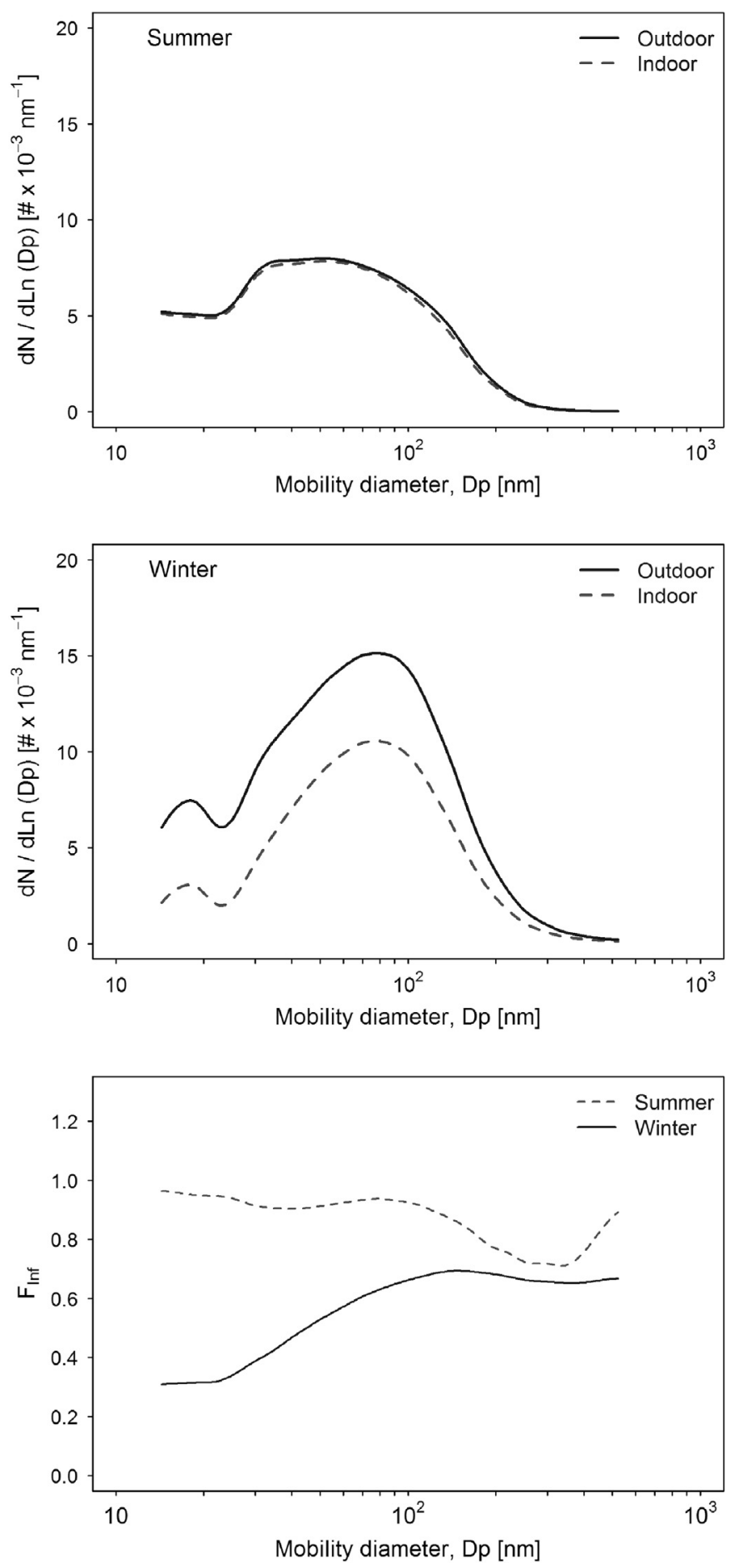

Fig. 2. Indoor and outdoor particle size distribution during the two monitoring periods (upper and mid panel) and Infiltration factor $\left(F_{\text {inf }}\right)$ in relation to mobility diameter $(\mathrm{Dp})$ (lower panel).

and higher acid species concentrations will favor the formation of ammonium nitrates, as a product of gas-phase reactions between ammonia and nitric acid (Zhang et al., 2011). The absolute concentration levels of sulfates remained quite constant across seasons, with higher relative contributions during summer, when the relative contributions of nitrates decreased, which is in accordance with the commonly observed trend in Northern Italy (Ricciardelli et al., 2017; Cattaneo et al., 2016) (Fig. 3). Fig. 3 shows indeed that the main difference in the chemical composition between summer and winter is related to nitrates and 
Table 2

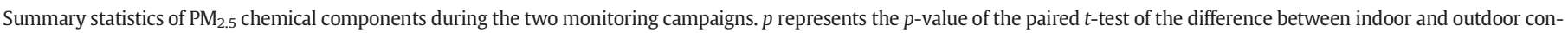
centrations; $\mathrm{R}^{2}$ is the determination coefficient.

\begin{tabular}{|c|c|c|c|c|c|c|c|c|}
\hline & \multicolumn{4}{|l|}{ Summer } & \multicolumn{4}{|l|}{ Winter } \\
\hline & \multirow{2}{*}{$\frac{\text { Indoor }}{\text { Mean (min-max) }}$} & \multirow{2}{*}{$\frac{\text { Outdoor }}{\text { Mean (min-max) }}$} & \multirow[t]{2}{*}{$p$} & \multirow[t]{2}{*}{$\mathrm{R}^{2}$} & \multirow{2}{*}{$\frac{\text { Indoor }}{\text { Mean (min-max) }}$} & \multirow{2}{*}{$\frac{\text { Outdoor }}{\text { Mean (min-max) }}$} & \multirow[t]{2}{*}{$p$} & \multirow[t]{2}{*}{$\mathrm{R}^{2}$} \\
\hline & & & & & & & & \\
\hline $\mathrm{OC}$ & $2.85(2.17-3.36)$ & $2.96(2.06-3.74)$ & 0.32 & 0.94 & $7.52(5.35-9.76)$ & $10.4(8.4-12.96)$ & $<\mathbf{0 . 0 1}$ & 0.96 \\
\hline $\mathrm{EC}$ & $1.08(0.92-1.29)$ & $1.12(0.94-1.36)$ & 0.06 & 0.98 & $3.03(2.86-3.23)$ & $3.79(3.06-4.72)$ & 0.26 & 0.02 \\
\hline TC & $3.93(3.1-4.63)$ & $4.08(3.05-5.1)$ & 0.21 & 0.96 & $10.55(8.21-12.75)$ & $14.19(11.46-17.68)$ & 0.03 & 0.94 \\
\hline $\mathrm{NH}_{4}$ & $0.59(0.42-0.92)$ & $0.61(0.47-0.96)$ & 0.3 & 0.98 & $1.05(0.06-3.06)$ & $4.03(1.93-7.89)$ & 0.02 & 0.99 \\
\hline $\mathrm{NO}_{3}$ & $0.39(0.2-0.49)$ & $0.53(0.35-1)$ & 0.3 & 0.03 & $3.28(0.86-8.42)$ & $10.81(5.04-21)$ & 0.02 & 0.98 \\
\hline $\mathrm{SO}_{4}$ & $2.04(0.53-4)$ & $2.17(0.6-4.12)$ & $<\mathbf{0 . 0 1}$ & 0.99 & $1.92(0.94-2.78)$ & $2.48(1.64-3.34)$ & $<\mathbf{0 . 0 1}$ & 0.96 \\
\hline As & $0.57(0.25-1.22)$ & $0.62(0.26-1.33)$ & 0.08 & 0.98 & $1.19(0.24-2.61)$ & $1.56(0.36-3.49)$ & 0.12 & 0.99 \\
\hline $\mathrm{Fe}$ & $96.31(71.92-142.89)$ & $112.94(75.52-154.34)$ & 0.2 & 0.36 & $126.75(63.87-226.33)$ & $208.85(93.37-331.05)$ & 0.08 & 0.85 \\
\hline Mn & 3.59 (1.83-5.97) & $3.91(0.86-6.35)$ & 0.48 & 0.74 & $6.13(2.7-9.37)$ & $8.95(3.27-13.65)$ & 0.08 & 0.96 \\
\hline V & $0.87(0.3-1.59)$ & $0.87(0.22-1.86)$ & 0.95 & 0.98 & $0.7(0.57-0.95)$ & $0.52(0.22-0.9)$ & 0.07 & 0.92 \\
\hline $\mathrm{Cd}$ & $0.1(0.04-0.21)$ & $0.1(0.04-0.23)$ & 0.77 & 0.98 & $0.2(0.06-0.39)$ & $0.26(0.08-0.5)$ & 0.05 & 0.99 \\
\hline $\mathrm{Pb}$ & $3.24(1.54-6.85)$ & $3.4(1.59-7)$ & 0.05 & 0.99 & $7.68(1.44-17.42)$ & $9.96(1.98-22.5)$ & 0.1 & 0.99 \\
\hline Sn & $1.29(0.83-1.85)$ & $1.14(0.78-1.56)$ & $<\mathbf{0 . 0 1}$ & 0.96 & $2.89(1.45-5.05)$ & $3.93(1.91-6.65)$ & 0.02 & 0.98 \\
\hline $\mathrm{Sb}$ & $0.86(0.46-1.3)$ & $0.86(0.47-1.35)$ & 0.91 & 0.96 & $0.94(0.32-1.98)$ & $1.39(0.49-2.81)$ & 0.05 & 0.99 \\
\hline La & $0.04(0.03-0.05)$ & $0.04(0.03-0.05)$ & 0.37 & 0.76 & $0.14(0.05-0.27)$ & $0.22(0.05-0.4)$ & 0.18 & 0.92 \\
\hline
\end{tabular}

Bold emphases means statistically significant association $(\mathrm{p}<0.05)$.

$\mathrm{OC}, \mathrm{EC}, \mathrm{TC}, \mathrm{NH}_{4}, \mathrm{NO}_{3}, \mathrm{SO}_{4}$ are reported in $\mu \mathrm{g} \mathrm{m}^{-3}$; the other chemical species in $\mathrm{ng} \mathrm{m}^{-3}$.

sulfates with the latter increasing indoors from $11 \%$ during winter to $29 \%$ during summer and the former dropping from $19 \%$ to $6 \%$. The increased load of sulfates during summer, even more evident comparing

\section{Summer - Indoor}

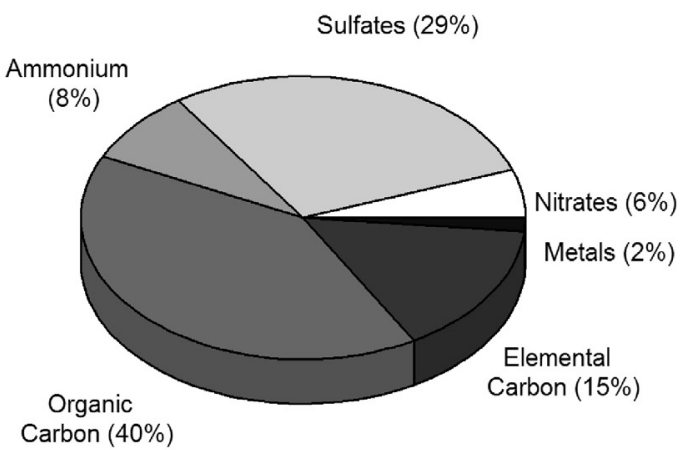

\section{Winter - Indoor}

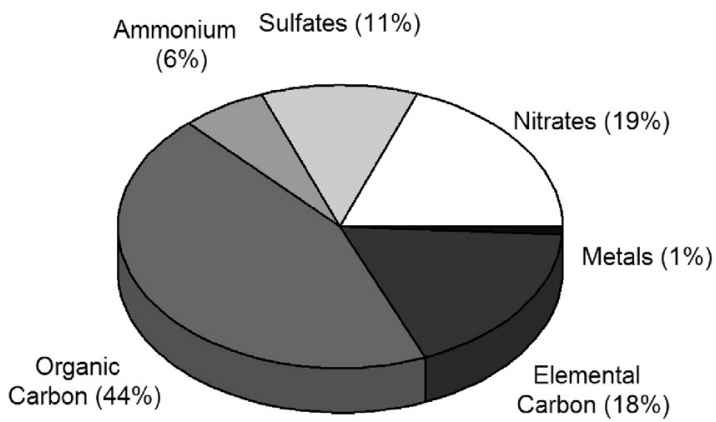

indoor concentrations, is noteworthy because most studies carried out in mid-latitudes, and specifically in the Mediterranean area, assigned an important role to sulfates (Basagaña et al., 2015). Among elements,

\section{Summer - Outdoor}

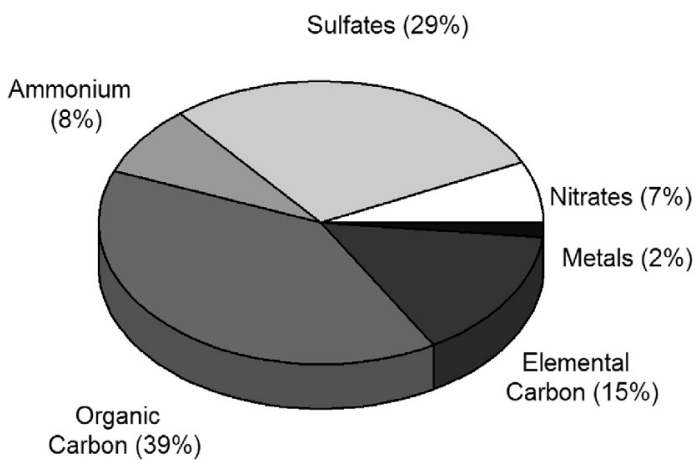

Winter - Outdoor

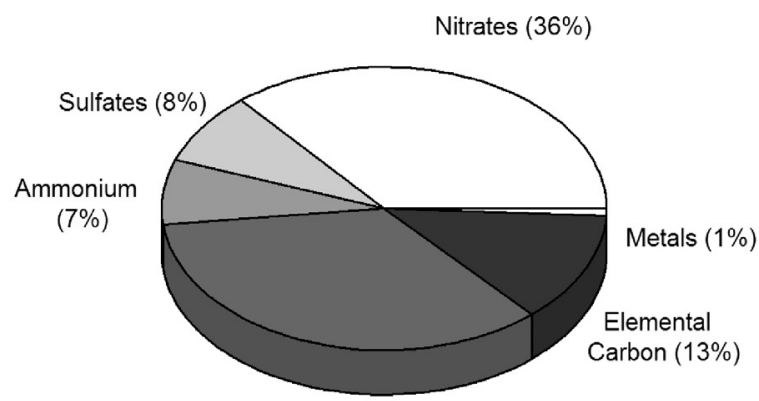

Organic

Carbon (35\%)

Fig. 3. Indoor and outdoor mean contributions of the major chemical components of $\mathrm{PM}_{2.5}$ during the two monitoring periods. 
only V showed slightly higher absolute concentration values during summer.

Beside the seasonal variation, the ionic species showed also the largest indoor/outdoor differences among all of the chemical components. The most evident variations were identified for $\mathrm{NH}_{4}^{+}$(mean I/O ratio equal to 0.97 and 0.19 for the warm and cold season, respectively) and $\mathrm{NO}_{3}^{-}$(mean $\mathrm{I} / \mathrm{O}$ ratio equal to 0.83 and 0.25 for the warm and cold season, respectively), which are commonly present in the atmosphere as the semi-volatile $\mathrm{NH}_{4} \mathrm{NO}_{3}$ molecule (Seinfeld and Pandis, 2006). During the transport from outdoor to indoor environments, particle-bound compounds are subject to a change in environmental conditions, with generally decreased $\mathrm{RH}$ and increased temperatures, especially during wintertime. These parameters (temperature in particular) govern the gas-particulate partitioning process (Ohura et al., 2004). Thus, when penetrating indoor, a semi-volatile molecule tend to move from the particulate to the gaseous phase (Harrison et al., 1994; Lunden et al., 2003; Sangiorgi et al., 2013), as occurred in our study for $\mathrm{NH}_{4} \mathrm{NO}_{3}$. Moreover, it is worth noting that PM-bound nitrates are mainly distributed in the coarser fractions of $\mathrm{PM}_{2.5}$ (Zhuang et al., 1999; Cuccia et al., 2013) that infiltrate indoor with less efficiency when windows are closed because of mechanical reasons (Jones et al., 2000; Urso et al., 2015).

Fig. 4 shows the season-specific scatter plot between indoor and outdoor data for the pooled chemical components. Some outliers were identified and highlighted in the figure. Most of them are related to the above discussed changes in concentrations of nitrates and ammonium during transport from outdoors to indoors. In winter, vanadium concentrations were elevated and all nitrate and ammonium concentrations reduced. In addition to significantly lower values of infiltration factors, nitrates and ammonium showed a sink effect during winter due to their volatility. On the contrary, infiltration factor very similar to the pooled estimates were found for vanadium which showed an unexpected source effect (intercept significantly $>0$ ), although we didn't find any explanation of the apparent presence of indoor sources for this element.

Regression of standardized chemical components showed significant differences between seasons. The summer and winter regression slopes of pooled data (calculated without outliers) were 0.9 and 0.73 , respectively, with a very high determination coefficient $\left(R^{2}=0.96\right)$. Including outliers would have marginal effects on the regression parameters with summer and winter infiltration factors decreasing to 0.84 and 0.69 , respectively. Much higher impact would be observed with regards to determination coefficients which decreased from 0.96 to 0.86 for summer and 0.71 for winter data.

Table 3 shows the results of the LOEO analysis. Our findings suggest low sensitivity of the regression slopes to individual components. With regard to ion components significant differences were found only for nitrates and sulfates during the summer season and for ammonium and nitrates during the winter season. Significant differences were found also for $\mathrm{Pb}$ and $\mathrm{Sn}$ during summer.

\subsection{Strengths and weaknesses}

To our knowledge, this is the first experimental study aiming at assessing the seasonal variations of infiltration factors of different particle metrics in a test house with the use of a ventilation protocol. Some
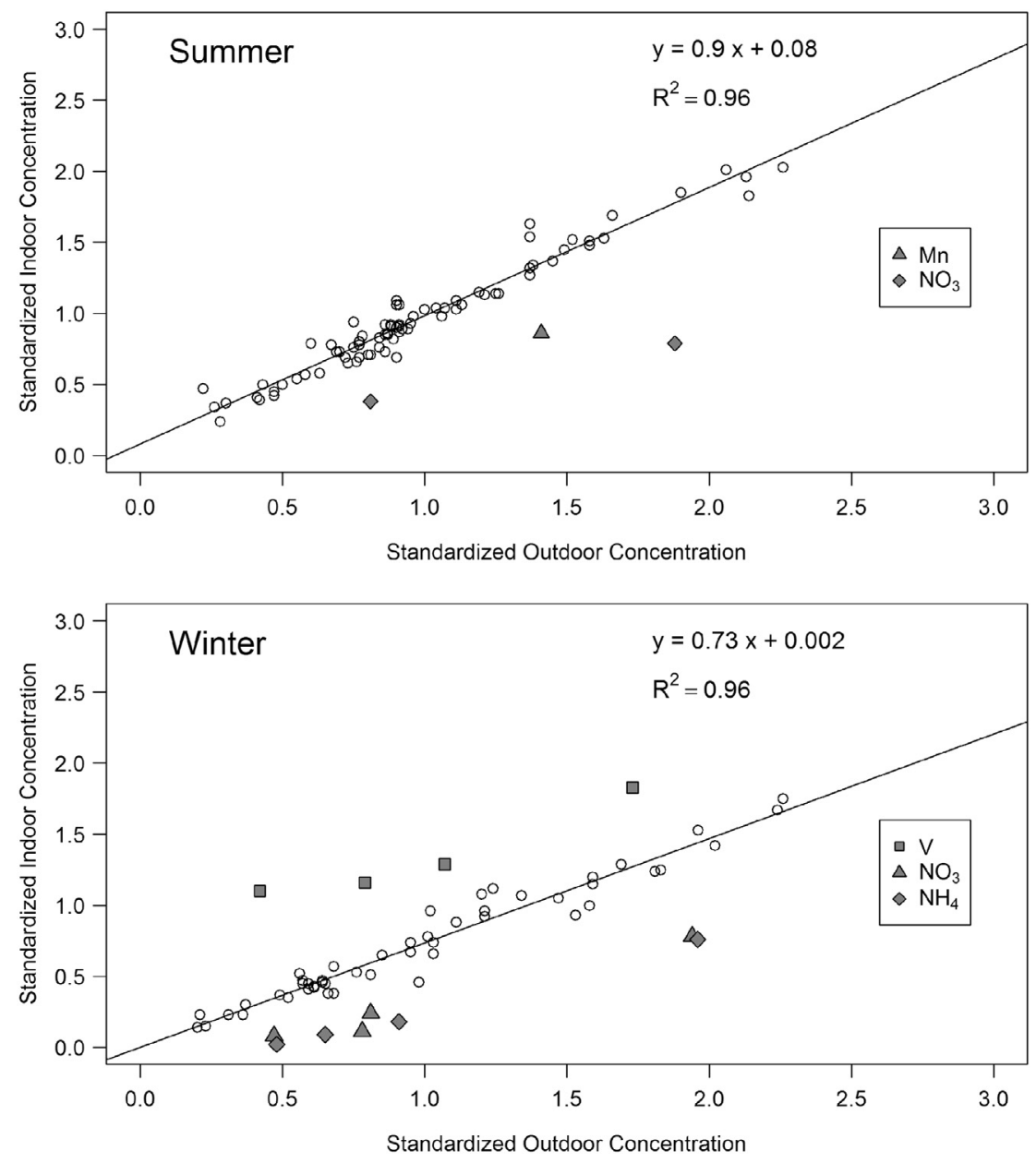

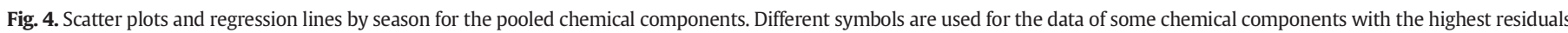
from the regression lines. 
Table 3

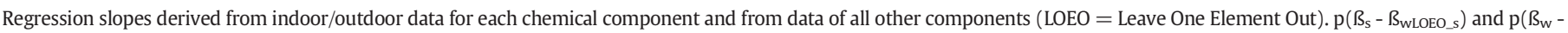

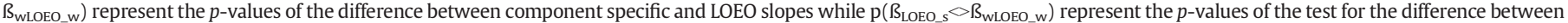
the summer and winter LOEO slopes.

\begin{tabular}{|c|c|c|c|c|c|c|c|}
\hline & \multicolumn{2}{|c|}{ Summer } & \multicolumn{5}{|c|}{ Winter } \\
\hline & $\beta_{s}$ & $\beta_{\text {LOEO_s }}$ & $\beta_{w}$ & $\beta_{\text {LOEO_w }}$ & 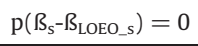 & 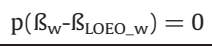 & 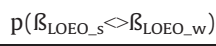 \\
\hline OC & 0.71 & 0.84 & 0.76 & 0.69 & 0.35 & 0.50 & 0.05 \\
\hline EC & 0.88 & 0.84 & 0.60 & 0.70 & 0.60 & 0.67 & 0.06 \\
\hline TC & 0.75 & 0.84 & 0.72 & 0.69 & 0.40 & 0.77 & 0.05 \\
\hline $\mathrm{NH}_{4}$ & 0.94 & 0.84 & 0.51 & 0.71 & 0.40 & $<\mathbf{0 . 0 1}$ & 0.06 \\
\hline $\mathrm{NO}_{3}$ & 0.07 & 0.89 & 0.49 & 0.71 & 0.04 & 0.03 & $<0.01$ \\
\hline $\mathrm{SO}_{4}$ & 0.99 & 0.82 & 1.08 & 0.68 & $<\mathbf{0 . 0 1}$ & 0.13 & 0.06 \\
\hline $\mathrm{Fe}$ & 0.97 & 0.84 & 0.68 & 0.69 & 0.20 & 0.84 & 0.06 \\
\hline As & 0.90 & 0.83 & 0.74 & 0.68 & 0.35 & 0.40 & 0.07 \\
\hline $\mathrm{Mn}$ & 0.64 & 0.86 & 0.60 & 0.70 & 0.31 & 0.38 & 0.03 \\
\hline V & 0.84 & 0.84 & 0.58 & 0.70 & 0.98 & 0.46 & 0.03 \\
\hline $\mathrm{Cd}$ & 0.86 & 0.84 & 0.80 & 0.68 & 0.78 & 0.09 & 0.05 \\
\hline $\mathrm{Pb}$ & 0.99 & 0.82 & 0.78 & 0.68 & $<\mathbf{0 . 0 1}$ & 0.13 & 0.08 \\
\hline Sn & 1.18 & 0.83 & 0.79 & 0.69 & 0.05 & 0.34 & 0.06 \\
\hline $\mathrm{Sb}$ & 0.94 & 0.83 & 0.73 & 0.69 & 0.31 & 0.57 & 0.06 \\
\hline La & 0.91 & 0.84 & 0.64 & 0.70 & 0.81 & 0.81 & 0.06 \\
\hline
\end{tabular}

Bold emphases means statistically significant association $(\mathrm{p}<0.05)$.

previous information is available thanks to modeling studies (Shi et al., 2017). The relevance of this study builds not only in the understanding why the health effects of PM are much higher during the warm season but also in the possibility of using these seasonal differences to improve and enrich the current knowledge about the particle metrics that could be most responsible of PM toxicity. Moreover, beside the seasonal variability, this type of investigation may represent a valid support in epidemiological studies focused on specific chemical $\mathrm{PM}_{2.5}$ components. Indeed, as demonstrated from the $\mathrm{F}_{\text {inf }}$ analysis, the actual exposure levels of the general population mostly depend on indoor concentrations of air pollutants of outdoor origin and could be lower than the corresponding ambient values because of specific infiltration characteristics, especially in the absence of indoor sources (e.g. sulfates, nitrates). Consequently, a bias in effect estimates will occur if the exposure assessment in epidemiological studies dealing with health effects of PM and individual chemical species in the PM mixture is only based on ambient data or models that do not take into account the indoor/outdoor differences. In this regard, we found that the indoor exposure to some chemical components such as $\mathrm{NO}_{3}^{-}, \mathrm{NH}_{4}^{+}, \mathrm{SO}_{4}^{2-}$ (but also $\mathrm{Pb}$ and $\mathrm{Sn}$ in summer) should be affected by additional deviations from the normal indoor/outdoor gradient affecting PM ambient levels, due to their different infiltration factors with respect to the rest of PM components.

Nevertheless, although the general validity and meaning of the experimental simulation presented in this paper, other studies with a similar approach are encouraged to verify our findings in other types of apartment, different ventilation protocols and, hopefully, longer monitoring periods. In addition, the possibility to extend the simulation to the general population and also to people having air conditioned in their houses would be a significant improvement and extension of our goals.

A possible weakness of the study is also the lack of some components in the chemical speciation of $\mathrm{PM}_{2.5}$ even though the selection of chemical species to be analyzed was based on a criterion related to a supposed relevance for human health.

\section{Conclusions}

We presented the results of an experimental study carried out using a simulated ventilation pattern in a test house. The study was focused on the analysis of the relationships between ambient and indoor concentrations of different particle metrics in order to interpret the apparent seasonal differences in PM toxicity highlighted in several epidemiological and toxicological studies.

Our data showed that part of the increased risk associated to $\mathrm{PM}_{2.5}$ exposure during summer could be ascribed to the protective effect of building during winter, when the $\mathrm{PM}_{2.5}$ infiltration factors are significantly lower compared to the summer period. This means that a unit increase in ambient concentrations results in an higher increase in indoor concentrations during the warm season compared to the cold one. As a consequence, in epidemiological studies, which assign exposure by means of ambient data, unit risks tend to appear elevated during summer.

However we also observed that seasonal variation of the relationship between indoor and ambient $\mathrm{PM}_{2.5}$ concentrations were unable to entirely explain the differences in the health effects found in epidemiological studies. Therefore other possible causes were investigated considering other particle metrics, such as particle size distribution and $\mathrm{PM}_{2.5}$ chemical composition.

With regards to the particle size distribution, a marked decrease of nucleation mode particles passing from outdoors to indoors during the winter season was observed. This causes higher concentration of nano and ultrafine particles indoors during summer. Even though it is still not clearly established by the scientific literature if and how nucleation mode particles are more toxic than larger particles, it is generally believed that the ability of smaller particles to penetrate deeply in alveoli and also through the epithelial barrier should make them more dangerous. Useful hints about the interpretation of the increased PM toxicity during summer came also from the $\mathrm{PM}_{2.5}$ chemical composition. In particular we observed indoor $\mathrm{PM}_{2.5}$ during the warm season poorer in nitrates and ammonium and richer in sulfates and vanadium compared to winter. This was caused both by variation of chemical composition of ambient $\mathrm{PM}_{2.5}$ and by some component specific infiltration factors. Thus, a bias in effect estimates will occur if the exposure assessment in epidemiological studies is only based on ambient data or models that do not take into account the infiltration factors of PM and the specific behaviour or some specific chemical constituents of the PM mixture (i.e. semi-volatile compounds in the winter period). The variation of the infiltration factor of PM with size should also be considered in studies aimed at investigating the health effects of PM size fractions in human populations.

\section{Acknowledgments}

This work was conducted as part of the 'Supersito' project, which was supported and financed by the Emilia-Romagna Region (DRG no. 428/10 and DRG no. 1971/13) and the Regional Agency for Prevention, Environment and Energy (DDG no. 29/2010). Data analysis and presentation were also supported by the Nordic Research Board (NordForsk) under the Nordic Programme on Health and Welfare project \#75007 (Nordic WelfAir), Academy of Finland projects PM SIZEx (133792), BATMAN (285672) and intramural funding of the participating institutes. 


\section{Appendix A. Supplementary data}

Supplementary data to this article can be found online at https://doi. org/10.1016/j.scitotenv.2018.01.217.

\section{References}

Alessandrini, E.R., Stafoggia, M., Faustini, A., Berti, G., Canova, C., De Togni, A., Di Biagio, K., Gherardi, B., Giannini, S., Lauriola, P., Pandolfi, P., Randi, G., Ranzi, A., Simonato, L. Zauli Sajani, S., Cadum, E., Forastiere, F., on behalf of the EpiAir2 Study Group, 2016. Association between short-term exposure to $\mathrm{PM}_{2.5}$ and $\mathrm{PM}_{10}$ and mortality in susceptible subgroups: a multisite case-crossover analysis of individual effect modifiers. Am. J. Epidemiol. 184, 744-754.

Andersen, R., Fabi, V., Toftum, J., Corgnati, S.P., Olesen, B.W., 2013. Window opening behaviour modelled from measurements in Danish dwellings. Build. Environ. 69, 101-113.

ASHRAE, 1997. Evaluating building IAQ and ventilation with indoor carbon dioxide.Available online:. http://fire.nist.gov/bfrlpubs/build97/PDF/b97044.pdf (accessed 27 July 2017).

Basagaña, X., Jacquemin, B., Karanasiou, A., Ostro, B., Querol, X., Agis, D., Alessandrini, E. Alguacil, J., Artiñano, B., Catrambone, M., de la Rosa, J.D., Díaz, J., Faustini, A., Ferrari, S., Forastiere, F., Katsouyanni, K., Linares, C., Perrino, C., Ranzi, A., Ricciardelli, I. Samoli, E., Zauli-Sajani, S., Sunyer, J., Stafoggia, M., MED-PARTICLES Study group, 2015. Short-term effects of particulate matter constituents on daily hospitalizations and mortality in five South-European cities: results from the MED-PARTICLES project. Environ. Int. 75, 151-158.

Beelen, R., Raaschou-Nielsen, O., Stafoggia, M., Andersen, Z.J., Weinmayr, G., Hoffmann, B., Wolf, K., Samoli, E., Fischer, P., Nieuwenhuijsen, M., Vineis, P., Xun, W.W., Katsouyanni, K., Dimakopoulou, K., Oudin, A., Forsberg, B., Modig, L., Havulinna, A.S., Lanki, T., Turunen, A., Oftedal, B., Nystad, W., Nafstad, P., De Faire, U., Pedersen, N.L. Östenson, C.G., Fratiglioni, L., Penell, J., Korek, M., Pershagen, G., Eriksen, K.T., Overvad, K., Ellermann, T., Eeftens, M., Peeters, P.H., Meliefste, K., Wang, M., Buenode-Mesquita, B., Sugiri, D., Krämer, U., Heinrich, J., de Hoogh, K., Key, T., Peters, A., Hampel, R., Concin, H., Nagel, G., Ineichen, A., Schaffner, E., Probst-Hensch, N., Künzli, N., Schindler, C., Schikowski, T., Adam, M., Phuleria, H., Vilier, A., ClavelChapelon, F., Declercq, C., Grioni, S., Krogh, V., Tsai, M.Y., Ricceri, F., Sacerdote, C. Galassi, C., Migliore, E., Ranzi, A., Cesaroni, G., Badaloni, C., Forastiere, F., Tamayo, I. Amiano, P., Dorronsoro, M., Katsoulis, M., Trichopoulou, A., Brunekreef, B., Hoek, G. 2014. Effects of long-term exposure to air pollution on natural-cause mortality: an analysis of 22 European cohorts within the multicentre ESCAPE project. Lancet 383, 785-795.

Bigi, A., Harrison, R.M., 2010. Analysis of the air pollution climate at a central urban background site. Atmos. Environ. 44, 2004-2012.

Biggeri, A., Baccini, M., Bellini, P., Terracini, B., 2005. Meta-analysis of the Italian studies of short-term effects of air pollution (MISA), 1990-1999. Int. J. Occup. Environ. Health 11, 107-122.

Brown, K.W., Sarnat, J.A., Suh, H.H., Coull, B.A., Spengler, J.D., Koutrakis, P., 2008. Ambient site, home outdoor and home indoor particulate concentrations as proxies of personal exposures. J. Environ. Monit. 10, 1041-1051.

Brunekreef, B., Holgate, S.T., 2002. Air pollution and health. Lancet 360, 1233-1242.

Cattaneo, A., Peruzzo, C., Garramone, G., Urso, P., Ruggeri, R., Carrer, P., Cavallo, D.M., 2011. Airborne particulate matter and gaseous air pollutants in residential structures in Lodi province, Italy. Indoor Air 21, 489-500.

Cattaneo, A., Fermo, P., Urso, P., Perrone, M.G., Piazzalunga, A., Tarlassi, J., Carrer, P., Cavallo, D.M., 2016. Particulate-bound polycyclic aromatic hydrocarbon sources and determinants in residential homes. Environ. Pollut. 218, 16-25.

Charron, A., Harrison, R.M., 2003. Primary particle formation from vehicle emissions during exhaust dilution in the roadside atmosphere. Atmos. Environ. 37, 4109-4119.

Chen, C., Zhao, B., Weschler, C.J., 2012. Indoor exposure to "outdoor $\mathrm{PM}_{10}$ ": assessing its influence on the relationship between $\mathrm{PM}_{10}$ and short-term mortality in U.S. cities. Epidemiology 23, 870-878.

Corsini, E., Vecchi, R., Marabini, L., Fermo, P., Becagli, S., Bernardoni, V., Caruso, D., Corbella L., Dell'Acqua, M., Galli, C.L., Lonati, G., Ozgen, S., Papale, A., Signorini, S., Tardivo, R., Valli, G., Marinovich, M., 2017. The chemical composition of ultrafine particles and associated biological effects at an alpine town impacted by wood burning. Sci. Total Environ. 587-588, 223-231.

Costa, V., Bacco, D., Castellazzi, S., Ricciardelli, I., Vecchietti, R., Zigola, C., Pietrogrande, M.C., 2016. Characterization of carbonaceous aerosol in Emilia Romagna during the Supersito Project: influences of the thermal-optical measurement protocols. Atmos. Res. 167, 100-107.

Cuccia, E., Massabò, D., Ariola, V., Bove, M.C., Fermo, P., Piazzalunga, A., Prati, P., 2013. Sizeresolved comprehensive characterization of airborne particulate matter. Atmos. Environ. $67,14-26$.

Cyrys, J., Pitz, M., Bischof, W., Wichmann, H.E., Heinrich, J., 2004. Relationship between indoor and outdoor levels of fine particle mass, particle number concentrations and black smoke under different ventilation conditions. J. Expo. Anal. Environ. Epidemiol. $14,275-283$

Diapouli, E., Chaloulakou, A., Koutrakis, P., 2013. Estimating the concentration of indoor particles of outdoor origin: a review. J. Air Waste Manag. Assoc. 63, 1113-1129.

Dimitroulopoulou, C., 2012. Ventilation in European dwellings: a review. Build. Environ. 47, 109-125.

Ebelt, S.T., Wilson, W.E., Brauer, M., 2005. Exposure to ambient and nonambient components of particulate matter: a comparison of health effects. Epidemiology 16, 396-405.
Fuller, C.H., Brugge, D., Williams, P.L., Mittleman, M.A., Lane, K., Durant, J.L., Spengler, J.D 2013. Indoor and outdoor measurements of particle number concentration in nearhighway homes. J. Expo. Sci. Environ. Epidemiol. 23, 506-512.

Haldi, F., Robinson, D., 2009. Interactions with window openings by office occupants. Build. Environ. 44 (12), 2378-2395.

Hamed, A., Joutsensaari, J., Mikkonen, S., Sogacheva, L., Dal Maso, M., Kulmala, M., Cavalli, F., Fuzzi, S., Facchini, M.C., Decesari, S., Mircea, M., Lehtinen, K.E.J., Laaksonen, A., 2007. Nucleation and growth of new particles in Po Valley, Italy. Atmos. Chem. Phys. 7, 355-376.

Hänninen, O., Lebret, E., Ilacqua, V., Katsouyanni, K., Künzli, N., Srám, R.J., Jantunen, M.J. 2004. Infiltration of ambient PM2.5 and levels of indoor generated non-ETS PM2.5 in residences of four European cities. Atmos. Environ. 38, 6411-6423.

Hänninen, O., Hoek, G., Mallone, S., Chellini, E., Katsouyanni, K., Kuenzli, N., Gariazzo, C., Cattani, G., Marconi, A., Molnár, P., Bellander, T., Jantunen, M., 2011. Seasonal patterns of outdoor PM infiltration into indoor environments: review and meta-analysis of available studies from different climatological zones in Europe. Air Qual. Atmos. Health 4, 221-233.

Hänninen, O., Sorjamaa, R., Lipponen, P., Cyrys, J., Lanki, T., Pekkanen, J., 2013. Aerosol-based modelling of infiltration of ambient PM2.5 and evaluation against population-based measurements in homes in Helsinki, Finland. J. Aerosol Sci. 66, 111-122.

Hänninen, O., Rumrich, I., Asikainen, A., 2017. Challenges in estimating health effects of indoor exposures to outdoor particles: considerations for regional differences. Sci. Total Environ. 589, 130-135.

Harrison, R.M., Yin, J., 2000. Particulate matter in the atmosphere: which particle properties are important for its effects on health? Sci. Total Environ. 249, 85-101.

Harrison, R.M., Msibi, M.I., Kitto, A.M., Yamulki, S., 1994. Atmospheric chemical transformations of nitrogen compounds measured in the North Sea experiment, September 1991. Atmos. Environ. 28 (9), 1593-1599.

Harrison, R.M., Jones, A., Gietl, J., Yin, J., Green, D., 2012. Estimation of the contribution of brake dust, tire wear and resuspension to nonexhaust traffic particles derived from atmospheric measurements. Environ. Sci. Technol. 46, 6523-6529.

Herkel, S., Knapp, U., Pfafferott, J., 2008. Towards a model of user behaviour regarding the manual control of windows in office buildings. Build. Environ. 43, 588-600.

Jeong, C.H., Evans, G., 2009. Inter-comparison of a fast mobility particle sizer and a scanning mobility particle sizer intercorporating an ultrafine water-based condensation particle counter. Aerosol Sci. Technol. 43, 364-373.

Jeong, B., Jeong, J.W., Park, J.S., 2016. Occupant behavior regarding the manual control of windows in residential buildings. Energy Build. 127, 206-216.

Jones, N.C., Thornton, C.A., Mark, D., Harrison, R.M., 2000. Indoor/outdoor relationships of particulate matter in domestic homes with roadside, urban and rural locations. Atmos. Environ. 34, 2603-2612.

Kaminski, H., Kuhlbusch, T.A.J., Rath, S., Götz, U., Sprenger, M., Wels, D., Polloczek, J. Bachmann, V., Dziurowitz, N., Kiesling, H.-J., Schwiegelshohn, A., Monz, C., Dahmann, D., Asbach, C., 2013. Comparability of mobility particle sizers and diffusion chargers. J. Aerosol Sci. 57, 156-178.

Kelly, F.J., Fussell, J.C., 2012. Size, source and chemical composition as determinants of toxicity attributable to ambient particulate matter. Atmos. Environ. 60, 504-526.

Kim, S.E., Lim, Y.H., Kim, H., 2015. Temperature modifies the association between particulate air pollution and mortality: a multi-city study in South Korea. Sci. Total Environ. 524, 376-383.

Lanzinger, S., Schneider, A., Breitner, S., Stafoggia, M., Erzen, I., Dostal, M., Pastorkova, A. Bastian, S., Cyrys, J., Zscheppang, A., Kolodnitska, T., Peters, A., UFIREG study group 2016. Associations between ultrafine and fine particles and mortality in five central European cities - results from the UFIREG study. Environ. Int. 88, 44-52.

Long, C.M., Suh, H.H., Catalano, P.J., Koutrakis, P., 2001. Using time- and size-resolved particulate data to quantify indoor penetration and deposition behavior. Environ. Sci. Technol. 35, 2089-2099.

Lunden, M.M., Revzan, K.L., Fischer, M.L., Thatcher, T.L., Littlejohn, D., Hering, S.V., Brown, N.J., 2003. The transformation of outdoor ammonium nitrate aerosols in the indoor environment. Atmos. Environ. 37, 5633-5644.

Ma, Y., Chen, R., Pan, G., Xu, X., Song, W., Chen, B., Kan, H., 2011. Fine particulate air pollution and daily mortality in Shenyang. China. Sci. Total Environ. 409, 2473-2477.

Meier, R., Schindler, C., Eeftens, M., Aguilera, I., Ducret-Stich, R.E., Ineichen, A., Davey, M., Phuleria, H.C., Probst-Hensch, N., Tsai, M.Y., Künzli, N., 2015a. Modeling indoor air pollution of outdoor origin in homes of SAPALDIA subjects in Switzerland. Environ. Int. 82, 85-91

Meier, R., Eeftens, M., Phuleria, H.C., Ineichen, A., Corradi, E., Davey, M., Fierz, M., DucretStich, R.E., Aguilera, I., Schindler, C., Rochat, T., Probst-Hensch, N., Tsai, M.Y., Künzli, N. 2015b. Differences in indoor versus outdoor concentrations of ultrafine particles, $\mathrm{PM}_{2.5}$, PM absorbance and $\mathrm{NO}_{2}$ in Swiss homes. J. Expo. Sci. Environ. Epidemiol. 25, 499-505.

Meng, Q.Y., Turpin, B.J., Korn, L., Weisel, C.P., Morandi, M., Colome, S., Zhang, J.J., Stock, T., Spektor, D., Winer, A., Zhang, L., Lee, J.H., Giovanetti, R., Cui, W., Kwon, J., Alimokhtari, S., Shendell, D., Jones, J., Farrar, C., Maberti, S., 2005. Influence of ambient (outdoor) sources on residential indoor and personal $\mathrm{PM}_{2.5}$ concentrations: analyses of RIOPA data. J. Expo. Anal. Env. Epidemiol. 15, 17-28.

Nawrot, T.S., Torfs, R., Fierens, F., De Henauw, S., Hoet, P.H., Van Kersschaever, G., De Backer, G., Nemery, B., 2007. Stronger associations between daily mortality and fine particulate air pollution in summer than in winter: evidence from a heavily polluted region in western Europe. J. Epidemiol. Community Health 61, 146-149.

Ohura, T., Amagai, T., Fusaya, M., Matsushita, H., 2004. Polycyclic aromatic hydrocarbons in indoor and outdoor environments and factors affecting their concentrations. Environ. Sci. Technol. 38, 77-83

Park, A.K., Hong, Y.C., Kim, H., 2011. Effect of changes in season and temperature on mortality associated with air pollution in Seoul, Korea. J. Epidemiol. Community Health 65, 368-375. 
Peters, A., Ruckerl, R., Cyrys, J., 2011. Lessons from air pollution epidemiology for studies of engineered nanomaterials. J. Occup. Environ. Med. 53, S8-S13.

Raaschou-Nielsen, O., Andersen, Z.J., Beelen, R., Samoli, E., Stafoggia, M., Weinmayr, G. Hoffmann, B., Fischer, P., Nieuwenhuijsen, M.J., Brunekreef, B., Xun, W.W. Katsouyanni, K., Dimakopoulou, K., Sommar, J., Forsberg, B., Modig, L., Oudin, A Oftedal, B., Schwarze, P.E., Nafstad, P., De Faire, U., Pedersen, N.L., Ostenson, C.G., Fratiglioni, L., Penell, J., Korek, M., Pershagen, G., Eriksen, K.T., Sørensen, M., Tjønneland, A., Ellermann, T., Eeftens, M., Peeters, P.H., Meliefste, K., Wang, M., Bueno-de-Mesquita, B., Key, T.J., de Hoogh, K., Concin, H., Nagel, G., Vilier, A., Grioni, S., Krogh, V., Tsai, M.Y., Ricceri, F., Sacerdote, C., Galassi, C., Migliore, E., Ranzi, A., Cesaroni, G., Badaloni, C., Forastiere, F., Tamayo, I., Amiano, P., Dorronsoro, M., Trichopoulou, A., Bamia, C., Vineis, P., Hoek, G., 2013. Air pollution and lung cancer incidence in 17 European cohorts: prospective analyses from the European Study of Cohorts for Air Pollution Effects (ESCAPE). Lancet Oncol. 14, 813-822.

Raaschou-Nielsen, O, Beelen, R., Wang, M. Hoek, G, Andersen, ZJ., Hoffmann, B. Stafoggia, M., Samoli, E., Weinmayr, G., Dimakopoulou, K., Nieuwenhuijsen, M., Xun, W.W., Fischer, P., Eriksen, K.T., Sørensen, M., Tjønneland, A., Ricceri, F., de Hoogh, K. Key, T., Eeftens, M., Peeters, P.H., Bueno-de-Mesquita, H.B., Meliefste, K., Oftedal, B., Schwarze, P.E., Nafstad, P., Galassi, C., Migliore, E., Ranzi, A., Cesaroni, G., Badaloni, C., Forastiere, F., Penell, J., De Faire, U., Korek, M., Pedersen, N., Östenson, C.G. Pershagen, G., Fratiglioni, L., Concin, H., Nagel, G., Jaensch, A., Ineichen, A., Naccarati, A., Katsoulis, M., Trichpoulou, A., Keuken, M., Jedynska, A., Kooter, I.M., Kukkonen, J., Brunekreef, B., Sokhi, R.S., Katsouyanni, K., Vineis, P., 2016. Particulate matter air pollution components and risk for lung cancer. Environ. Int. 87, 66-73.

REVIHAAP, 2013. Review of evidence on health aspects of air pollution - REVIHAAP Project. Technical Report. World Health Organization (WHO), Regional Office for Europe, Copenhagen.

Ricciardelli, I., Bacco, D., Rinaldi, M., Bonafè, G., Scotto, F., Trentini, A., Bertacci, G., Ugolini, P., Zigola, C., Rovere, F., Maccone, C., Pironi, C., Poluzzi, V., 2017. A three-year investigation of daily $\mathrm{PM}_{2.5}$ main chemical components in four sites: the routine measurement program of the Supersito Project (Po Valley, Italy). Atmos. Environ. 152, 418-430.

Samoli, E., Stafoggia, M., Rodopoulou, S., Ostro, B., Declercq, C., Alessandrini, E., Díaz, J. Karanasiou, A., Kelessis, A.G., Le Tertre, A., Pandolfi, P., Randi, G., Scarinzi, C., ZauliSajani, S., Katsouyanni, K., Forastiere, F., MED-PARTICLES Study Group, 2013. Associations between fine and coarse particles and mortality in Mediterranean cities: results from the MED-PARTICLES project. Environ. Health Perspect. 121, 932-938.

Sangiorgi, G., Ferrero, L., Ferrini, B.S., Lo Porto, C., Perrone, M.G., Zangrando, R., Gambaro A., Lazzati, Z., Bolzacchini, E., 2013. Indoor airborne particle sources and semi-volatile partitioning effect of outdoor fine PM in offices. Atmos. Environ. 65, 205-214.

Seinfeld, J.H., Pandis, S.N., 2006. Atmospheric Chemistry and Physics, From Air Pollution to Climate Change. A Wiley-Interscience Pollution Publication, United States of America (ISBN-10: 0471720186).
Shi, S., Zhao, B., 2016. Occupants' interactions with windows in 8 residential apartments in Beijing and Nanjing. China. Build. Simul. 9, 221-231.

Shi, S., Chen, C., Zhao, B., 2017. Modifications of exposure to ambient particulate matter: tackling bias in using ambient concentration as surrogate with particle infiltration factor and ambient exposure factor. Environ. Pollut. 220, 337-347.

Stafoggia, M., Schwartz, J., Forastiere, F., Perucci, C., 2008. Does temperature modify the association between air pollution and mortality? A multicity case-crossover analysis in Italy. Am. J. Epidemiol. 167, 1476-1485.

Stranger, M., Potgieter-Vermaak, S.S., Van Grieken, R., 2009. Particulate matter and gaseous pollutants in residences in Antwerp, Belgium. Sci. Total Environ. 407, $1182-1192$

Tammet, H., Mirme, A., Tamm, E., 2002. Electrical aerosol spectrometer of Tartu University. Atmos. Res. 62, 315-324.

Urso, P., Cattaneo, A., Garramone, G., Peruzzo, C., Cavallo, D.M., Carrer, P., 2015. Identification of particulate matter determinants in residential homes. Build. Environ. 86, 61-69.

Wong, C.M., Vichit-Vadakan, N., Kan, H., Qian, Z., Teams, P., 2008. Public Health and Air Pollution in Asia (PAPA): a multicity study of short-term effects of air pollution on mortality. Environ. Health Perspect. 116, 1195-1202.

Yamamoto, N., Shendell, D.G., Winer, A.M., Zhang, J., 2010. Residential air exchange rates in three major US metropolitan areas: results from the Relationship Among Indoor, Outdoor, and Personal Air Study 1999-2001. Indoor Air 20, 85-90.

Yi, O., Hong, Y.C., Kim, H., 2010. Seasonal effect of $\mathrm{PM}_{10}$ concentrations on mortality and morbidity in Seoul, Korea: a temperature-matched case-crossover analysis. Environ. Res. 110, 89-95.

Zauli-Sajani, S., Ricciardelli, I., Trentini, A., Bacco, D., Maccone, C., Castellazzi, S., Lauriola, P., Poluzzi, V., Harrison, R.M., 2015. Spatial and indoor/outdoor gradients in urban concentrations of ultrafine particles and $\mathrm{PM}_{2.5}$ mass and chemical components. Atmos. Environ. 103, 307-320.

Zauli-Sajani, S., Trentini, A., Rovelli, S., Ricciardelli, I., Marchesi, S., Maccone, C., Bacco, D., Ferrari, S., Scotto, F., Zigola, C., Cattaneo, A., Cavallo, D.M., Lauriola, P., Poluzzi, V., Harrison, R.M., 2016. Is particulate air pollution at the front door a good proxy of residential exposure? Environ. Pollut. 213, 347-358.

Zhang, T., Cao, J.J., Tie, X.X., Shen, Z.X., Liu, S.X., Ding, H., Han, Y.M., Wang, G.H., Ho, K.F., Qiang, J., Li, W.T., 2011. Water-soluble ions in atmospheric aerosols measured in Xi'an, China: seasonal variations and sources. Atmos. Res. 102, 110-119.

Zhou, B., Zhao, B., Guo, X., Chen, R., Kan, H., 2013. Investigating the geographical heterogeneity in $\mathrm{PM}_{10}$-mortality associations in the China Air Pollution and Health Effects Study (CAPES): a potential role of indoor exposure to $\mathrm{PM}_{10}$ of outdoor origin. Atmos. Environ. 75, 217-223.

Zhuang, H., Chan, C.K., Fang, M., Wexler, A.S., 1999. Size distributions of particulate sulfate, nitrate, and ammonium at a coastal site in Hong Kong. Atmos. Environ. 33, 843-853. 